\title{
Numerical Analysis of Compressed Masonry Columns
}

\author{
Aneta Libecajtová1* \\ 1 Department of Building Structures, Faculty of Civil Engineering, Czech Technical University in Prague, Thakurova 7, 16629 \\ Prague, Czech Republic \\ * Corresponding author, e-mail: aneta.libecajtova@fsv.cvut.cz
}

Received: 20 November 2019, Accepted: 19 April 2020, Published online: 22 May 2020

\begin{abstract}
This paper presents a three-demensional micro-model for an unreinforced masonry (URM) column and masonry columns reinforced by FRP wrapping (RM). The column with dimensions of $0.3 \times 0.3 \times 1 \mathrm{~m}$ was constituted by twelve rows of solid burnt bricks bonded by mortar joints. The RM column was wrapped in four external FRP sheets. A heterogeneous model, in which masonry units, mortar joints and reinforcement are materially and geometrically accurately described, was chosen. Both bricks and mortar are modelled with independent behavior in compression and tension. The FRP reinforcement is assumed to behave linear-elastically. The reinforcement was modelled under the assumption of perfect adhesion between the elastic FRP strips and the damageable masonry support. Numerical results are compared with experimental ones in order to confirm conclusions about the behavior of URM and RM columns under concentric compressive load determined based on the experimental part of the research program. The comparison between experimental and numerical findings shows good agreement and the adopted numerical model is suitable to predict the ultimate load and allows a better understanding of the behavior of brick masonry columns under concentric compression before and after reaching the ultimate load. For all simulations, the commercial software package ABAQUS was used.
\end{abstract}

Keywords

masonry, brick, mortar, FRP, compressive load, FEA

\section{Introduction}

Masonry structures have been used since ancient times and the protection of this architectural heritage should be considered as essential. The status of historical buildings and their treatment testify to the development of society. Non-invasive interventions are often desirable for maintaining the original building's nature. In the last two decades, high-strength fabrics have played a significant role in the stabilization and strengthening of masonry structures. Wrapping the load-bearing elements (in this case columns) in FRP sheets increases their load-bearing capacity and stability and reduces lateral strain of the structure. Fabrics' low weight does not impose extra load on the structure, concurrently, this method of strengthening is considered as highly effective and potentially reversible.

Several types of approaches based on micro- or macro-modelling can be applied to numerical analysis of masonry structures. Generally, the analysis of large-scale structures cannot be conducted through micro-modelling, i.e. each masonry unit, mortar joints and FRP sheets are modelled separately with distinct material parameters. This approach requires high computational costs even for elements with small dimensions. Considering these limitations homogeneous models are often carried out. The use of homogenized material properties can be debatable in terms of the relevancy of obtained results. Many recent authors deal with homogenization methods, and new approaches to obtaining homogenized properties, even non-linear, have been designed in the last couple years [1-3]. The first disadvantage is the limitation of their utilization only for the specific setup that they have been designed for. A low predictive value of local problems for irregular non-periodic masonry can be regarded as another disadvantage.

The bond between the masonry support and the FRP reinforcement has a significant influence on the effectiveness of strengthening by FRP wrapping. This issue has become experimentally [4-10] and theoretically [9-18] one of global research interests in the last few years. In general, several approaches to the simulation of debonding phenomena are available in the literature. Many authors have executed a numerical analysis of RM under the assumption of perfect adhesion [11-14, 16]. The advantage of this approach is that material characteristics of masonry 
units, mortar and reinforcement are required, not interface parameters. It can be expected that material characteristics for the constituents are known with good accuracy (laboratory testing, etc.). Another approach includes modelling of bond behavior using zero-thickness interface elements between FRP and masonry support [9, 10, 15, 18]. Within this approach, the non-linearities are concentrated at the FRP - masonry support interface, while FRP and the substrate can behave linear-elastically or a nonlinear material model can be adopted for masonry units. The most complex approach is modelling every single part of the structure (including glue) separately. The disadvantage of the last approach is the necessity of knowing a lot of material parameters that are usually difficult to obtain.

It is necessary to understand the behavior of a structure before and after applying the reinforcement for a suitable design of its remediation. Modern methods of structural analysis which include numerical modelling contribute to better understanding of structure's behavior and help prevent inappropriate interferences in historical structures.

The aim of this study is the confirmation of experimental conclusions and the investigation of the behavior of compressed masonry columns in detail, therefore, a heterogeneous micro-model that interprets accurately the real geometry and material properties, is considered as a suitable approach. The comparison of numerical and experimental results enables the verification of the reliability of adopted numerical models.

\section{Behavior of brick masonry columns under compressive loads}

Masonry can be considered as heterogeneous, anisotropic and quasi brittle material. Its heterogeneity is mainly caused by the assembly of two different materials - masonry units and mortar. The composition of masonry units and mortar itself results in a further contribution to the heterogeneous nature of masonry, as well as manufacturing, damage, cracking, degradation etc. All these influences cause an enormous scatter of mechanical characteristics of masonry.

A typical collapse mechanism of unreinforced compressed masonry structures is accompanied by a progressive growth of vertical cracks due to transversal tensile stresses caused by the contraction and mutual interaction between masonry units and mortar joints. The interaction between two materials in a real structure is ensured by the debonding resistance of masonry units and mortar. As a result of this mutual interaction, mortar, which has a lower Young's modulus (usually in historical buildings) and tends to develop greater lateral strains, is transversely compressed, while masonry units, on the contrary, are transversely in tension (Fig. 1(a)). The formation of vertical tensile cracks in masonry units (bricks) due to the tensile stresses caused by the lateral strain of more mechanically compliant mortar in bed joints (ratio of Young's modulus $\mathrm{Em}<\mathrm{Eu}$ ) precedes the appearance of continuous vertical cracks and the failure of the structure. In the case that bricks have a lower Young's modulus (Fig. 1(b)), and, consequently, tend to develop greater lateral strains, the mortar is subjected to transverse tension and bricks are transversely compressed [19].

\section{Numerical analysis}

\subsection{Brief description of experimental program}

The experimental program is part of the research projects DF12P01OVV037 and DG16P02M055, which are being carried out at the Faculty of Civil Engineering, CTU in Prague. The experimental part deals with an URM column and a RM column under concentric compressive load. The test specimens (Fig. 2) were made up of 12 rows of solid burnt bricks with dimensions of $290 \times 140 \times 65 \mathrm{~mm}$. Lime-cement mortar was used as a binder, mortar joints had a thickness equal to $20 \mathrm{~mm}$. A total height of the masonry column was $1000 \mathrm{~mm}$. The columns were reinforced by wrapping in one layer of carbon fabric sheets Tyfo SCH-41. The material properties of FRP used for reinforcement can be found in [20, 21]. Four FRP sheets

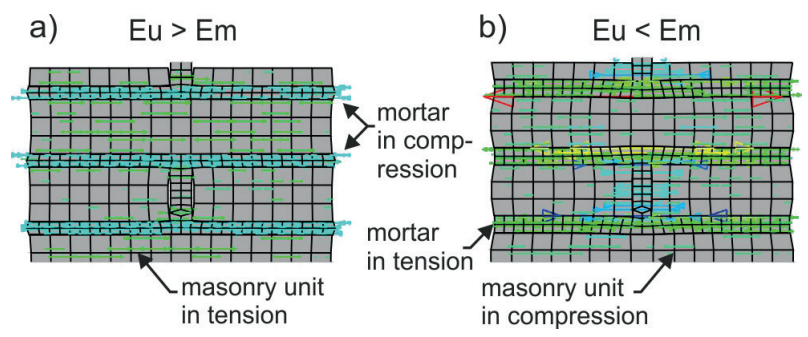

Fig. 1 Deformation (10x scaled in the horizontal direction) and horizontal stress trajectories. (a) $\mathrm{Eu}>\mathrm{Em}$; (b) $\mathrm{Eu}<\mathrm{Em}$

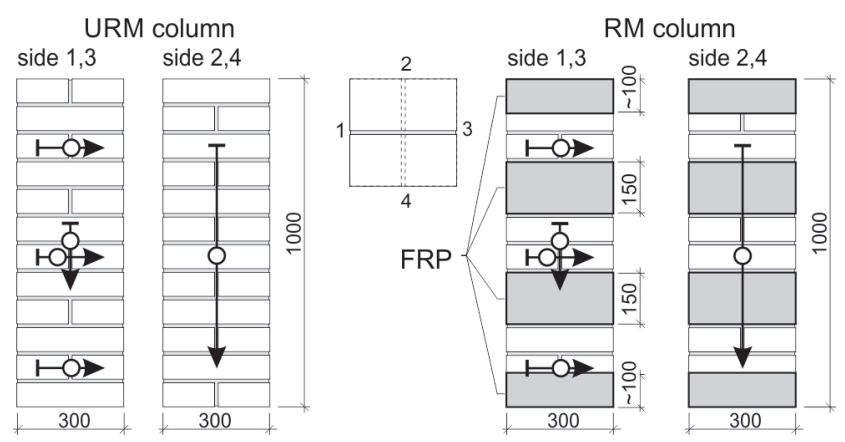

Fig. 2 Experimental setups 
were glued on the masonry support by means of two-component tixotrophic epoxy resin - in thirds of the column's height and at the column's head and toe with a width of $150 \mathrm{~mm}$ and $75 \mathrm{~mm}$, respectively.

The load was applied in the form of an increasing vertical force up to the masonry column's failure. The load was added in steps of $60 \mathrm{kN}$, which was $10 \%$ of the expected ultimate load of URM column. The strain distribution was obtained from strain gauges attached to the masonry surface, and vertical and horizontal deformations were measured by a linear variable differential transformer (LVDT).

\subsection{Summary of experimental results}

The loss of load-bearing capacity of the compressed URM column occurs in two phases with a different failure mechanism in each phase. Phase $\mathrm{I}$ is characterized by the formation and development of cracks that correspond to the direction of compressive stresses A gradual formation and development of tensile and shear vertical cracks result in the redistribution of loads and a non-uniform distribution of normal stresses. By the interconnection of vertical cracks accompanied by the division of the column into individual parts phase II occurs. The collapse of the URM column is usually caused by the loss of stability of partial "columns" $[22,23]$. The failure mechanism of the brick masonry column takes place predominantly in phase I and is strongly influenced by the tensile strength of the masonry units. This implies that with the same compressive strength of the masonry units used for the bricklaying of two pillars, a higher ultimate load is achieved for a pillar composed of masonry units with greater tensile strength.

The force-deformation curves displayed in Fig. 3 are the average values from the measurement by LVDT placed on sides 2 and 4. The experimentally obtained F-d curves for the URM and RM column show differences in the slope of the curve and in the ultimate load values. This confirms the complex character of masonry structures, which is moreover influenced by manufacturing and quality of used bricks and mortar.
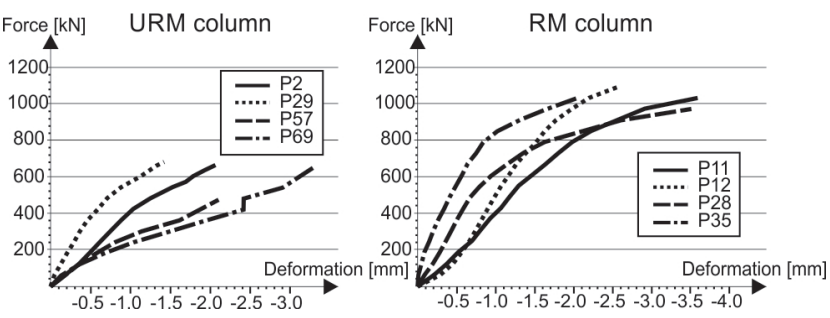

Fig. 3 Experimental Force-deformation diagram of URM and RM columns
However, experimental research demonstrates a significant effect of masonry reinforcement by FRP sheets on the ultimate load bearing capacity and rigidity of a compressed masonry column. The beneficial effect of the passive wrapping occurs with the formation of cracks at higher loads, which is followed by a progressive increase of the horizontal deformation and failure of the masonry column. FRP sheets take over part of tensile stresses and prevent further development of horizontal deformations, thereby allowing the masonry elements to reach values close to their ultimate compressive strength. The failure occurs in phase II, when the compressive strength of masonry elements is used. Reaching the ultimate load is accompanied by the crushing of masonry units and filling of bed joints and by a subsequent masonry final failure (Fig. 4). Based on the experimental research, the strengthening of a brick masonry column with individual FRP sheets placed in thirds of the column's height can be considered as optimum reinforcement. For more information see [20, 21, 24].

\subsection{FE model}

A detailed three-dimensional nonlinear finite element (FE) model of a brickwork column was made in the ABAQUS software with the aim of investigating the behavior of compressed URM and RM columns under concentric compressive loads and comparing numerically obtained results with experimental findings. With this aim the numerical model was created to correspond as closely as possible to the laboratory tested specimens. The column's plan dimensions were $0.3 \times 0.3 \mathrm{~m}$ and column's height was $1 \mathrm{~m}$ in all numerical simulations. Two steel plates were placed at the top edge and the bottom edge of the masonry column through which the boundary conditions were applied. The load was applied in the form of vertical deformation acting on the steel plate at the top edge of the masonry column (Fig. 5).

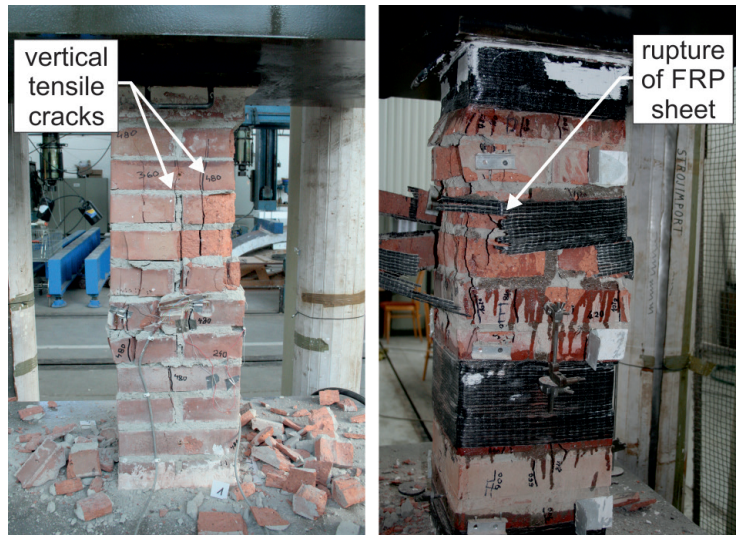

Fig. 4 URM and RM column's failure 

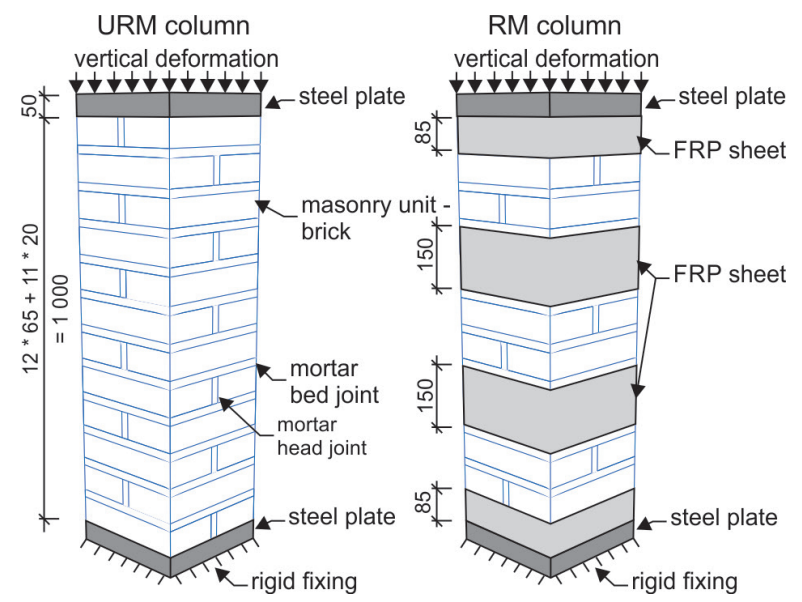

Fig. 5 Chart of a numerical model of URM and RM column
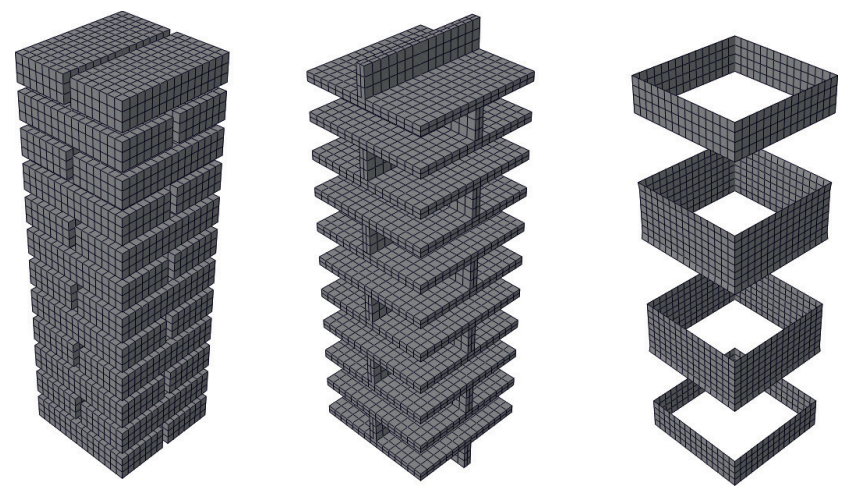

Fig. 6 Adopted FE mesh for bricks, mortar joints and FRP reinforcement

The adopted finite element mesh (Fig. 6) includes 8-node first order continuum (solid) elements (C3D8) to model bricks and mortar. The solid elements in ABAQUS can be used for linear analysis and for complex nonlinear analysis involving contact, plasticity, and large deformations. The general membrane elements (M3D4) used for the reinforcement discretization is a three-dimensional, 4-node membrane element. Membrane elements are used to represent thin surfaces in space that offer strength in the plane of the element but have no bending stiffness; for example, a thin rubber sheet that forms a balloon or thin stiffening components. General membrane elements should be used in three-dimensional models in which the deformation of the structure can evolve in three dimensions [27].

The maximal edge's size of the finite element is one third of the brick's height. The finite element net was refined at mortar joints (two finite elements per bed joint's thickness) for observing also the mortar joints stress character. The total number of finite elements for the URM column, or the RM column respectively, was 58 672, or 67 772, resp.
For the brick - mortar interface, a "hard" contact was assumed in the normal direction and frictional behavior (with a friction coefficient of 0.6) in the tangential direction. A perfect bond was assumed between the FRP strips and the masonry support without any adhesive layer. With this assumption, the thickness of the adhesive layer, which is difficult to define, is no longer needed. Concurrently, it is expected that the used epoxy glue is so rigid that failure must occur in the masonry and the additional (elastic) adhesive layer has a negligible influence on the RM column's response in compression.

\subsection{Constitutive model of masonry units and mortar}

The non-linear behavior of masonry units and mortar joints is modelled through the Concrete Damage Plasticity (CDP) model in this study. The CDP model has been successfully used in several cases for modeling masonry in the last few years $[12,25,26]$. All authors agreed that the CDP model has achieved a good agreement with experiments. The CDP model is directly available within the ABAQUS software and is used for modelling concrete and other quasi-brittle materials such as masonry. The CDP model assumes that the two main failure mechanisms are tensile cracking and compressive crushing. The model is based on the assumption of isotropic damage with different damage parameters in compression and tension. More information is available in the ABAQUS User's Guide [27].

Different elastic-plastic stress-strain relationships were taken into account, as illustrated in Fig. 7. The linear response of a material under uniaxial compression is followed by hardening after reaching the value of the initial yield stress $\sigma_{c 0}$. After the ultimate stress $\sigma_{c u}$ is reached, a softening part appears - the stress slowly descends while the strain rapidly grows.

In uniaxial tension, the stress-strain response follows a linear-elastic relationship until the maximal stress $\sigma_{t 0}$ is reached. After that, micro-cracks start to form, and a softening part occurs accompanied by stress drops with a concurrently increasing strain.
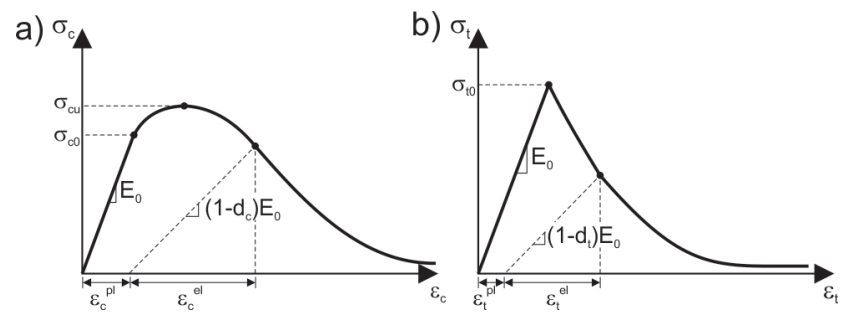

Fig. 7 Material response to uniaxial loading in tension (a) and compression (b) 
The degradation of material's elastic stiffness is characterized by two damage variables $d_{c}$ and $d_{t}$, which are related to equivalent plastic strain. If damage variables are equal to zero, the material is undamaged. The stress under uniaxial compression and tension loading for a damaged material is:

$\sigma_{c}=\left(1-d_{c}\right) E_{0}\left(\varepsilon_{c}-\tilde{\varepsilon}_{c}^{p l}\right)$,

$\sigma_{t}=\left(1-d_{t}\right) E_{0}\left(\varepsilon_{t}-\tilde{\varepsilon}_{t}^{p l}\right)$,

where $E_{0}$ is the initial elastic modulus (undamaged material), $\sigma_{c} / \sigma_{t}$ is the un-axial compressive / tensile stress, $\varepsilon_{c} /$ $\varepsilon_{t}$ is the total strain in compression / tension and $\tilde{\varepsilon}_{c}^{p l} / \tilde{\varepsilon}_{t}^{p l}$ is the equivalent plastic strain in compression / tension.

The CDP model is based on the assumption of a non-associated potential plastic flow: to describe the behavior of a material in the inelastic range the model uses the DruckerPrager hyperbolic function, thus, it is ensured the flow potential is continuous and smooth. The ABAQUS software enables ruling the smoothing by introducing a parameter, the so-called flow potential eccentricity, which corresponds to the length between the points of intersections of the line and the hyperbola with the $\mathrm{p}$ axis in the $\mathrm{p}-\mathrm{q}$ space (Fig. 8). The default value is 0.1 , smaller values may lead to convergence problems, if a material is subjected to a low confining pressure because of a very tight curvature [27].

The parameter $K_{c}$ allows the distortion of the DruckerPrager circle in the principal stress space, and the value equal to 0.667 , which is a default value from the ABAQUS software, makes Drucker-Prager more similar to the MohrCoulomb criterion (Fig. 9). The dilatancy angle for both masonry units (brick) and mortar is assumed equal to $10^{\circ}$, in agreement with scientific literature [28]. The CDP model takes into account the ratio between biaxial and uniaxial compressive yield stresses. The default value was originally meant for concrete, however bricks and mortar exhibit a similar behavior in compression as concrete, so the ratio value is assumed to be default, equal to 1.16 .

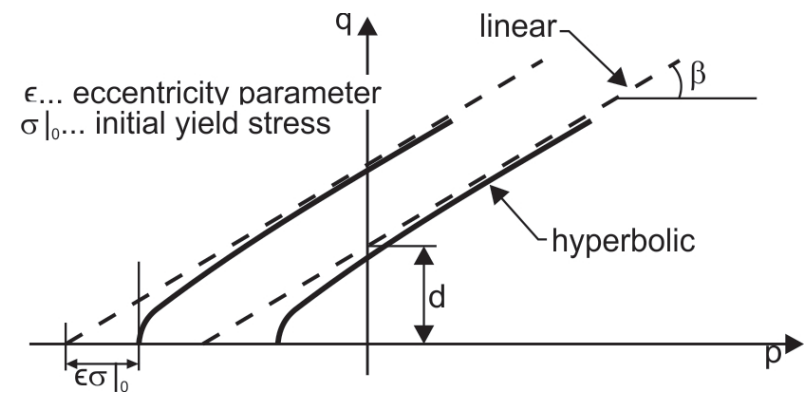

Fig. 8 Eccentricity parameter displayed in the p-q plane

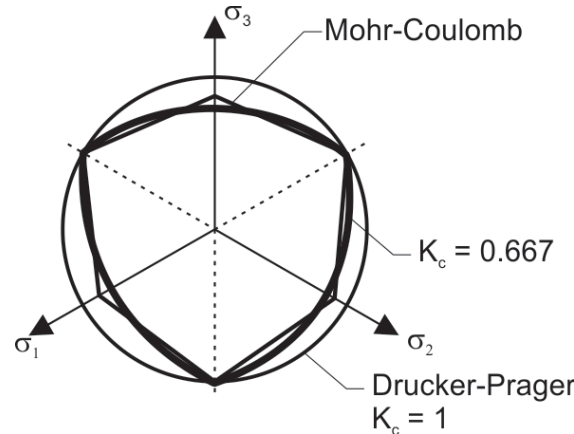

Fig. 9 Yield surface in the deviatoric plane

Material models exhibiting softening behavior and stiffness degradation can lead to convergence difficulties. The CDP model in ABABQUS allows introducing the viscosity parameter, which enables the use of a visco-plastic regularization and allows overcoming the convergence problems by using small increments. The default value is zero; a small value helps improve the rate of convergence in the softening branch, and, on the contrary a bigger value could compromise the obtained result. Viscosity parameter in this case is assumed equal to 0.002 [28]. All parameters adopted in the numerical model are summarized in Table 1.

It can be generally considered that the level of applied load in the numerical analysis is too low to damage FRP composites. Accordingly, in the analysis described here, the composites are treated as a linear elastic material. The linearelastic material parameters of all materials are in Table 2.

The brick and mortar are characterized by a large variance of mechanical properties and a general value of Young's modulus cannot be considered, Young's modulus of bricks and mortar were determined based on experimental testing. The average response of bricks and mortar in compression and tension that was used in the numerical simulation is displayed in Fig. 10. The linear-elastic characteristics of steel and FRP are more consistent, therefore, the value of Young's modulus of steel and FRP was found in literature [13].

Table 1 CDP parameters adopted in the numerical simulation

\begin{tabular}{lcccc}
\hline $\begin{array}{l}\text { DP } \\
\text { correction } \\
\text { parameter }\end{array}$ & $\begin{array}{c}\text { Dilation } \\
\text { angle } \psi\left[^{\circ}\right]\end{array}$ & Eccentricity & $\begin{array}{c}\text { Biaxial } / \\
\text { uniaxial } \\
\text { compressive } \\
\text { stress ratio }\end{array}$ & $\begin{array}{c}\text { Viscosity } \\
\text { parameter } \\
\mu\end{array}$ \\
\hline 0.667 & 10 & 0.1 & 1.16 & 0.002 \\
\hline
\end{tabular}

Table 2 Linear-elastic characteristics of materials

\begin{tabular}{lcccc}
\hline Model parameter/Material & Brick & Mortar & Steel & FRP \\
\hline E [MPa] & 3200 & 400 & 210000 & 230000 \\
$v[-]$ & 0.20 & 0.15 & 0.30 & 0.30 \\
\hline
\end{tabular}



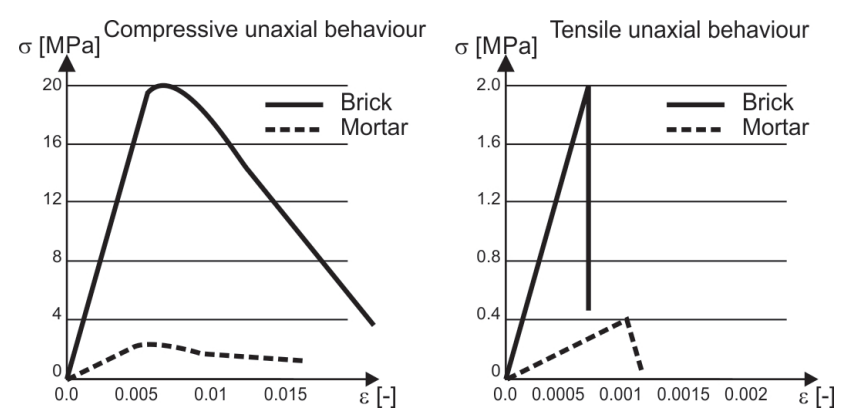

Fig. 10 Compressive and tensile behavior of bricks and mortar

\section{Discussion of obtained results}

Firstly, the cracking pattern of the laboratory tested URM and RM column was compared with the cracking prediction based on numerical analysis. The laboratory-tested columns were disassembled after reaching the ultimate load. For both solved types - URM and RM columns, the results from experimental testing clearly show cracking in the direction of middle principal stresses, normal to the direction of maximal principal stresses, respectively (Fig. 11-13). Numerical analysis enabled to describe a stress state preceding the failure of URM and RM columns.

In the case of the URM column, bricks are subjected to tensile stresses due to the contraction and mutual interaction between bricks and mortar. The maximal principal stress trajectories of URM run longitudinally with masonry units and cause their transversal cracking (Fig. 11), whilst the RM column's maximal principal stress trajectories radically change their direction as a result of FRP wrapping resulting in preventing to development of lateral strains (Fig. 12). The cracking is concentrated close to the masonry surface (reinforcement) and is converging at the corners of column. Reinforcement by FRP wrapping significantly changes the stress distribution compared to the URM column and transforms the failure mechanism of the compressed masonry column.

In the case of the RM column, a good agreement with experiments was also found at places without external FRP sheets. The maximal principal (cracking) stress causes splitting of the external parts of the RM column and thus the integral inner area for stress transfer is decreased (Fig. 13). The experimental crack pattern is consistent with the cracks' prediction based on the numerical simulation and corresponds to the character of middle principal stress trajectories.

Further, the numerical and experimental results were mutually compared in terms of the applied stress - strain curve (Figs. 14-15). In the case of the URM column, a good agreement was found with experiments in the values of the ultimate load and deformation properties. The numerical

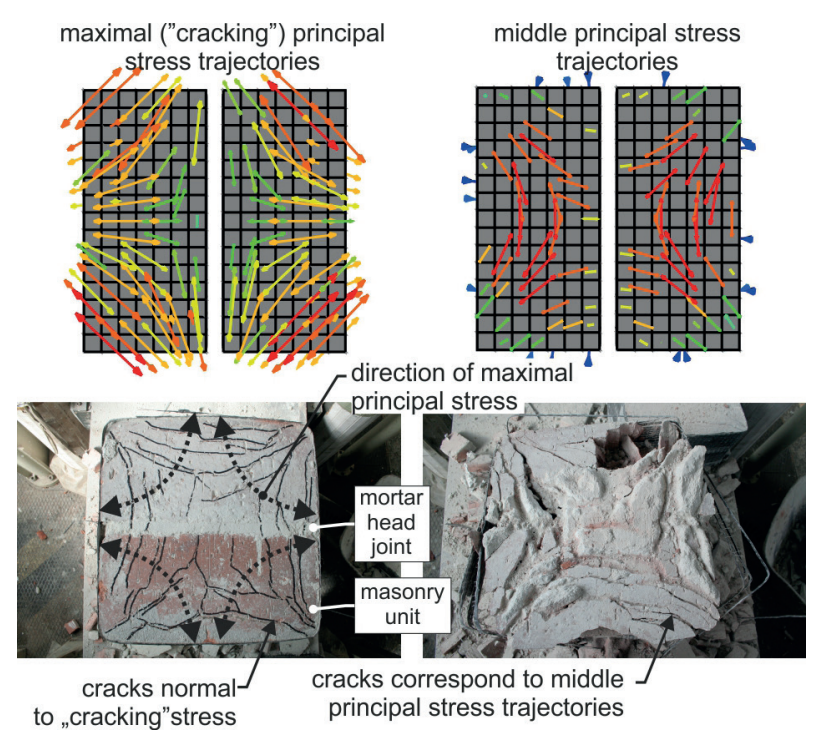

Fig. 11 Principal stress trajectories and experimentally observed cracking of the URM column

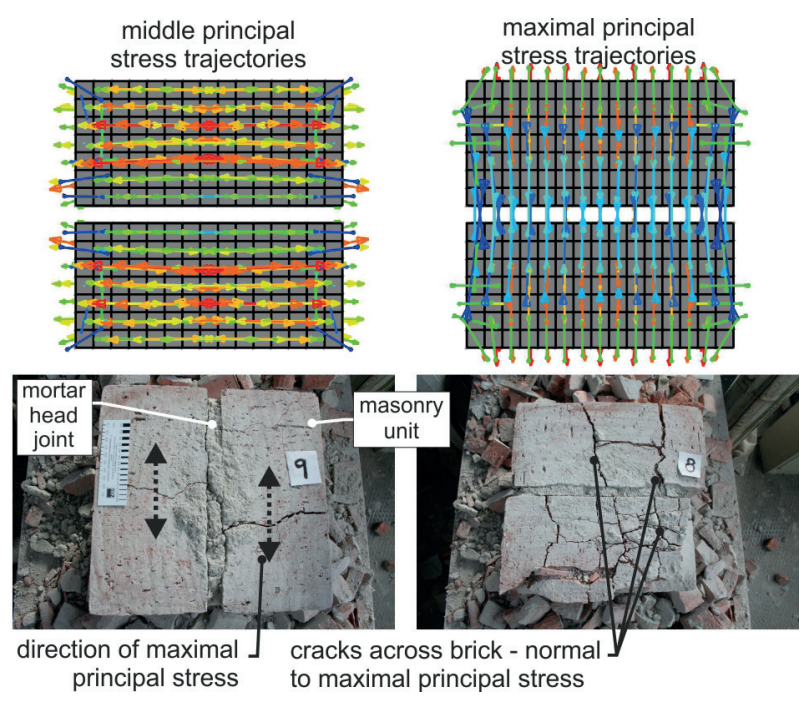

Fig. 12 Principal stress trajectories and experimentally observed cracking of the RM column

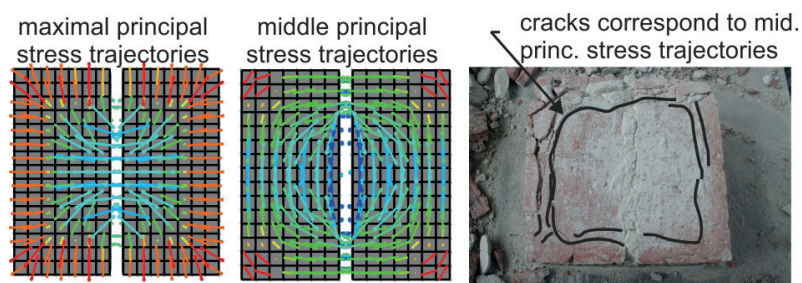

Fig. 13 Principal stress trajectories and experimentally observed cracking of the RM column at a horizontal cut without an external sheet

stress-strain curve shows the column's post peak behavior. The stress starts decreasing while the strain rapidly grows after reaching the ultimate load. The slope of the softening branch is not distinctly steep and the column keeps a significant part of its stiffness and load transfer ability. 


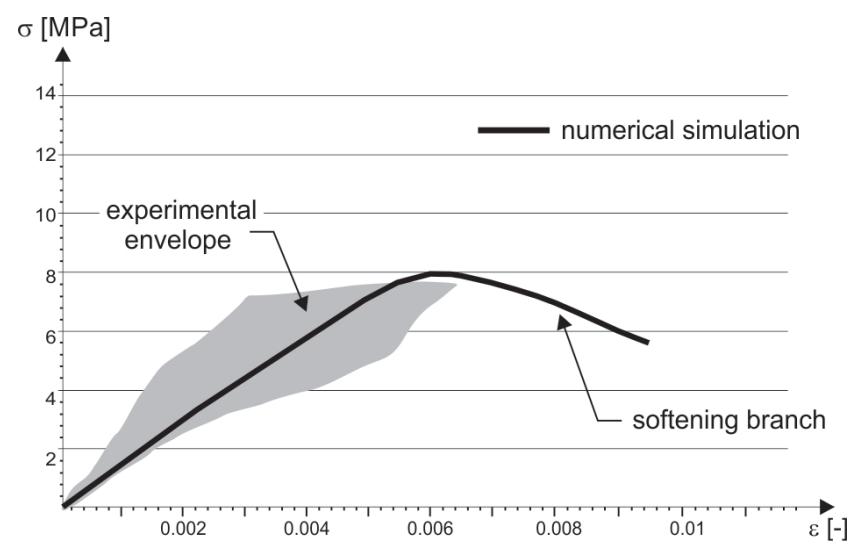

Fig. 14 Comparison of numerical and experimental results URM column

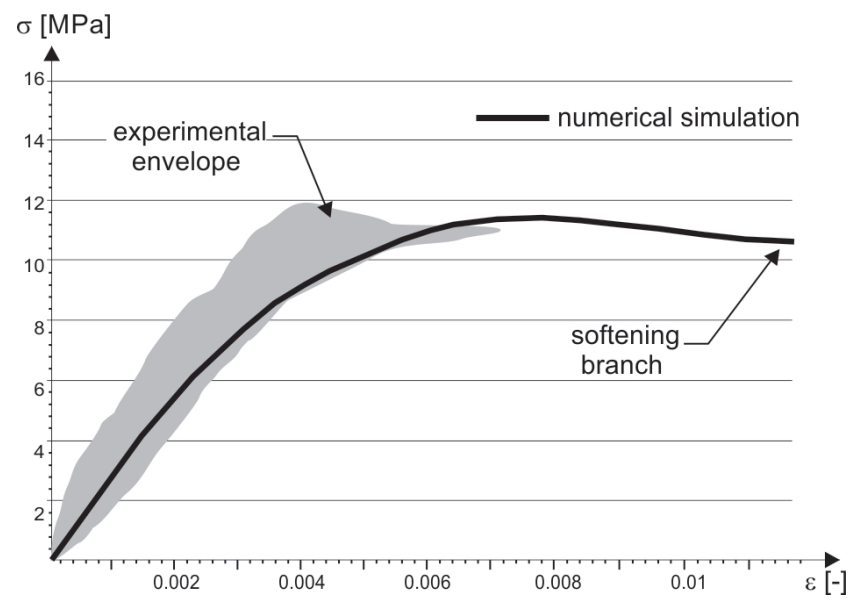

Fig. 15 Comparison of numerical and experimental results RM column

The behavior of the compressed URM column is strongly influenced by the mechanical properties of individual masonry components and other effects mentioned above. For this reason, the experimental envelope has a larger range. The masonry columns were laboratory-tested over several months and the quality of the masonry units and mortar was lightly variable.

The results from the numerical model of the RM column are in good agreement with experimental results in terms of the values of the ultimate load and the stress-strain diagram. The RM column in comparison with the URM column does not manifest a significant softening after reaching the ultimate load. The stress slightly decreases while the strain rapidly grows. The FRP sheets that are modeled under the assumption of linear-elastic behavior cause the preservation of the integrity of column and allow the column to continue to transfer a substantial part of the load even with progressively increasing strains.
The numerical model has proved the effect of FRP reinforcement on increasing the load-bearing capacity of the RM column. The maximal reached load value for the URM column was $720 \mathrm{kN}$, and for the RM column $1048 \mathrm{kN}$ in the numerical simulation of URM and RM columns. The ultimate load of the RM column corresponds to almost $150 \%$ of the ultimate load of the URM column (with the same input data). This is in agreement with experimental findings. The maximal value of the ultimate load of the URM column was $700 \mathrm{kN}$ in the experimental part. The columns reinforced by optimized wrapping (in thirds of the column's height and at its top and bottom edge) achieved the ultimate load by 1.3-1.6 times higher than the URM column [20, 21]. Good agreement between numerical and experimental result was also found in values of vertical strain. In numerical simulation of the URM column, vertical strain reached the value of 0.0061 when the ultimate load was reached. Maximal measured vertical strain of the URM columns was 0.0065 in experimental part that corresponds to $107 \%$ of the numerical value of vertical strain. The RM column reached the ultimate load with vertical strain of 0.0071 in numerical simulation and maximal measured value was 0.0072 in experimental part that corresponds to $101 \%$ of numerical value of vertical strain.

\section{Conclusions}

The adopted non-linear heterogeneous models of URM and RM columns show a good agreement with experimental findings in terms of the applied stress - strain curve, the cracking pattern, and the ultimate load value. The adopted numerical model is able to predict the ultimate load and the cracking pattern with good accuracy. The numerical simulations of URM and RM columns demonstrate a positive effect of FRP wrapping on the load-bearing capacity and deformation properties of compressed brick masonry columns. The results from the numerical simulation of RM column manifest an increase in ductility under concentric compressive loads in comparison with the URM column.

It is expected to use the adopted model that has been verified based on experiments to compare the response of URM columns, for example, in terms of changes in mortar joints' width or mechanical properties of masonry components. The modification and optimization of column's reinforcement through experiments is usually time consuming and expensive. The adopted numerical model can be used for the investigation of the behavior of a column that is reinforced by external sheets with other dimensions, in different positions or with a different number of sheets. 


\section{Acknowledgement}

The results were obtained with support from the research project DG16P02M055 - "Research and Development of Materials, Processes and Techniques for Restoration, Pre-

\section{References}

[1] Zucchini, A., Lourenço, P. B. "A micro-mechanical homogenization model for masonry: Application to shear walls", International Journal of Solids and Structures, 46(3-4), pp. 871-886, 2009. http://doi.org/10.1016/j.ijsolstr.2008.09.034

[2] Milani, G. "Simple homogenization model for the non-linear analysis of in-plane loaded masonry walls", Computers and Structures, 89(17-18), pp. 1586-1601, 2011.

http://doi.org/10.1016/j.compstruc.2011.05.004

[3] Stefanou, I., Sab, K., Heck, J.-V. "Three dimensional homogenization of masonry structures with building block of finite strength: A closed form strength domain", International Journal of Solids and Structures, 54, pp. 258-270, 2015. https://doi.org/10.1016/j.ijsolstr.2014.10.007

[4] Sassoni, E., Andreotti, S., Bellini, A., Mazzanti, B., Bignozzi, M. C., Mazzotti, C., Franzoni, E. "Influence of mechanical properties, anisotropy, surface roughness and porosity of brick on FRP debonding force", Composites Part B: Engineering, 108, pp. 257269, 2017.

https://doi.org/10.1016/j.compositesb.2016.10.020

[5] Ceroni, F., Leone, M., Rizzo, V., Bellini, A., Mazzotti, C. "Influence of mortar joints on the behavior of FRP materials bonded to different masonry substrates", Engineering Structures, 153, pp. 550-568, 2017.

https://doi.org/10.1016/j.engstruct.2017.10.030

[6] Vaculik, J., Visintin, P., Burton, N. G., Griffith, M. C., Seracino, R. "State-of-the-art review and future research directions for FRP-tomasonry bond research: Test methods and techniques for extraction of bond-slip behaviour", Construction and Building Materials, 183, pp. 325-345, 2018.

https://doi.org/10.1016/j.conbuildmat.2018.06.103

[7] Sassoni, E., Sarti, V., Bellini, A., Mazzotti, C., Franzoni, E. "The role of mortar joints in FRP debondig from masonry", Composites Part B: Engineering, 135, pp. 166-174, 2018. https://doi.org/10.1016/j.compositesb.2017.10.021

[8] Carloni, C., Subramaniam, K. V. "FRP-Masonry Debonding: Numerical and Experimental Study of the Role of Mortar Joints", Journal of Composites for Construction, 16(5), pp. 581-589, 2012. http://doi.org/10.1061/(ASCE)CC.1943-5614.0000282

[9] Barbieri, G., Biolzi, L., Bocciarelli, M., Cattaneo, S. "Pull out of FRP reinforcement from masonry pillars: Experimental and numerical results", Composites Part B: Engineering, 69, pp. 516$525,2015$.

https://doi.org/10.1016/j.compositesb.2014.10.025

[10] Mazzotti, C., Murgo, F. S. "Numerical and experimental study of GFRP.masonry inteface behavior: Bond evolution and role of the mortar layers", Composites Part B: Engineering, 75, pp. 212-225, 2015.

https://doi.org/10.1016/j.compositesb.2015.01.034 servation and Strengthening of Historic Masonry Structures, Surfaces and Systems for Preventive Care of Heritage Buildings Exposed to Anthropogenic and Natural Risks". The grant researcher is prof. Ing. Jiří Witzany, DrSc.

[11] Mrozek, M., Mrozek, D., Wawrzynek, A. "Numerical analysis of selection of the most effective configuration of CFRP composites reinforcement of masonry specimens", Composites Part B: Engineering, 70, pp. 189-200, 2015. https://doi.org/10.1016/j.compositesb.2014.11.016

[12] D'Altri, A. M., Carloni, C., de Miranda, S., Castellazzi, G. "Numerical modelling of FRP strips bonded to a masonry substrate", Composite Structures, 200, pp. 420-433, 2018. https://doi.org/10.1016/j.compstruct.2018.05.119

[13] Fedele, R., Milani, G. "A numerical insight into the response of masonry reinforced by FRP strips. The case of perfect adhesion"., Composite Structures, 92(10), pp. 2345-2357, 2010. https://doi.org/10.1016/j.compstruct.2010.03.014

[14] Fedele, R., Scaioni, M., Barazzetti, L., Rosati, G., Biolzi, L. "Delamination test on CFRP-reinforced masonry pillars: Optical monitoring and mechanical modeling", Cement and Concrete Composites, 45, pp. 243-254, 2014. https://doi.org/10.1016/j.cemconcomp.2013.10.006

[15] Ghiassi, B., Marcani, G., Oliveira, D. V., Lourenço, P. B. "Numerical analysis of bond behavior between masonry bricks and composite materials", Engineering Structures, 43, pp. 210-220, 2012. https://doi.org/10.1016/j.engstruct.2012.05.022

[16] Ghiassi, B., Oliveira, D. V., Lourenço, P. B., Marcari, G. "Numerical study of the role of mortar joints in the bond behavior of FRPstrengthened masonry", Composites Part B: Engineering, 46, pp. 21-30, 2013. https://doi.org/10.1016/j.compositesb.2012.10.017

[17] Freddi, F., Sacco, E. "An interphase model for the analysis of the masonry-FRP bond", Composite Structures, 138, pp. 322-334, 2016. https://doi.org/10.1016/j.compstruct.2015.11.041

[18] Ceroni, F., de Felice, G., Grande, E., Malena, M., Murgo, F., Sacco, E., Valuzzi, M. R. "Analytical and numerical modeling of composite-to-brick bond", Materials and Structures, 47, pp. 19872003, 2014.

https://doi.org/10.1617/s11527-014-0382-8

[19] Maroušková, A. "Masonry Column Reinforced by FRP Wrapping: Behavior and Numerical Analysis", Applied Mechanics and Materials, 825, pp. 27-30, 2016. https://doi.org/10.4028/www.scientific.net/AMM.825.27

[20] Witzany, J., Čejka, T., Zigler, R. "Failure mechanism of compressed short brick masonry column confined with FRP strips", Construction and Building Materials, 63, pp. 180-188, 2014. https://doi.org/10.1016/j.conbuildmat.2014.04.041

[21] Witzany, J., Zigler, R. "Stress State Analysis and Failure Mechanisms of Masonry Columns Reinforced with FRP under Concentric Compressive Load", Polymers, 8(5), Article number: 176, 2016. http://doi.org/10.3390/polym8050176 
[22] Witzany, J., Čejka, T., Zigler, R. "Determining residual load-bearing capacity of existing masonry pillars", Stavební Obzor, 17, pp. 257-265, 2008. (in Czech)

[23] Witzany, J., Čejka, T., Zigler, R. "Increase in Load-Bearing Capacity and Ductility of Strengthened Masonry Pillars", presented at CICE 2012 - The 6th International Conference on FRP Composites in Civil Engineering, Rome, Italy, June, 13-15, 2012.

[24] Witzany, J., Čejka, T., Zigler, R. "Problem of Masonry Strengthening with Carbon- and Glass Fibre Fabric", Procedia Engineering, 14, pp. 2086-2093, 2011.

https://doi.org/10.1016/j.proeng.2011.07.262

[25] Bertolesi, E., Milani, G., Fagone, M., Rotunno, T.; Grande, E. "Micro-mechanical FE numerical model for masonry curved pillars reinforced with FRP strips subjected to single lap shear tests", Composite Structures, 201, pp. 916-931, 2018.

http://doi.org/10.1016/j.compstruct.2018.06.111
[26] Milani, G., Valente, M., Fagone, M., Rotunno, T., Alessandri, C. "Advanced non-linear numerical modelling of masonry groin vaults of major historical importance: St John Hospital case study in Jeruzalem", Engineering Structures, 194, pp. 458-476, 2019. https://doi.org/10.1016/j.engstruct.2019.05.021

[27] Dassault Systemes "ABAQUS User's Guide 6.13", [online] Available at: http://media.3ds.com/support/simulia/public/v613/ installation-and-licensing-guides/books/sgb/default.htm?startat $=$ ch05s $03 . h t m 1$

[28] Milani, G., Valente, M., Alessandri, C. "The narthex of the Church of the Navity in Bethlehem: A non-linear finite elements approach to predict the structural damage", Computers and Structures, 207, pp. 3-18, 2018.

https://doi.org/10.1016/j.compstruc.2017.03.010 